\title{
ASPECTOS BIOLÓGICOS E SOCIOECONÔMICOS DA PESCA ESPORTIVA NO “DECK DO PESCADOR” DE SANTOS (SP, BRASIL)
}

\author{
BARRELLA, W. ${ }^{1,2,3,4, *}$; CACHOLA, N. ${ }^{2}$; RAMIRES, M. ${ }^{1,2,3}$ \& ROTUNDO, M.M. ${ }^{4}$
1. Programa de Pós Graduação em Sustentabilidade de Ecossistemas Costeiros e Marinhos (ECO- MAR) - Universidade Santa Cecília/UNISANTA, Santos, SP, Brasil. \\ 2. Graduação do curso de Ciências Biológicas da Universidade Santa Cecília (UNISANTA). \\ 3. FIFO - Fisheries and Food Institute, Santos, SP, Brasil. \\ 4. Acervo Zoológico da Universidade Santa Cecília (AZUSC-UNISANTA), Santos, SP, Brasil. \\ *Corresponding author: walterbarrella@gmail.com
}

\begin{abstract}
Barrella, W.; Cachola, N.; Ramires, M. \& Rotundo, M.M., (2016). Aspectos biológicos e socioeconômicos da pesca esportiva no "deck do pescador" de Santos (SP, Brasil). Braz. J. Aquat. Sci. Technol. 20(1). elSSN 1983-9057. DOI: $10.14210 /$ bjast.v20n1. Sport fishing is one of the categories of leisure fastest growing in the world today. In Brazil it is also practiced as a sport or leisure, noncommercial purposes. However, few studies are conducted in order to manage this activity, making it sustainable. This study aimed to analyze sport fishing, practiced the "Fisherman's deck" (Santos, SP, Brazil), describing their biological characteristics and the socioeconomic profile of the participants. Through observations and interviews were analyzed 150 fishermen, ages 12 and 82 years, 85\% male. The majority (56\%) has a college degree and resides near the fishing spot. The target species are swordfish (Trichiurus lepturus), bass (Centropomus spp.), Hake (Cynoscion spp.), betara (Menticirrhus americanus), corvina (Micropogonias furnieri) and hake-yellow (Macrodon atricauda). Three types of fishing, bottom fishing, surface and crab were identified. Fishermen indicated that fish stocks have declined due to increased commercial fishing and pollution.
\end{abstract}

Keywords: Urban fishing, Estuary, Fisheries management.

\section{INTRODUÇÃO}

A pesca esportiva é uma das categorias de turismo que mais cresce no mundo, sendo praticada como esporte ou lazer, sem fins comerciais, com objetivo secundário de captura de peixe para consumo pessoal (FAO, 1997 e 2012; Pitcher, 1999; Prado, 1999; Soares, 2001). A pesca desportiva ou amadora é praticada por brasileiro ou estrangeiro, com equipamentos ou petrechos previstos em legislação específica, tendo por finalidade o lazer ou o desporto (Lei № 11.959, de 29 de Junho de 2009; Instrução Normativa Interministerial MPA/MMA N 09, de 13 de Junho de 2012).

Por muito tempo a pesca esportiva foi considerada como de baixo impacto, e que não provoca redução nos estoques nem nas populações de peixes capturados. Entretanto, pesquisas recentes mostraram que esse tipo de pesca tem sido um fator influente para tal diminuição (Cooke \& Cowx, 2006). Segundo Freire (2010) em estimativas globais não há informações concretas da quantidade dos peixes capturados na pesca esportiva, isso por que a maior parte dos países não tem a obrigação de registrar as capturas provenientes de atividades recreativas. Porém, Cooke \& Cowx (2004) indicam que capturas globais de lazer podem variar de 2 e 10,9 milhões de toneladas por ano. Os efeitos cumulativos associados à pesca esportiva são preocupantes tanto para a conservação dos recursos pesqueiros como também para a manutenção dos ecossistemas aquáticos (O'Toole et al., 2009).

A maior parte da população humana se concentra nos centros urbanos, por isto, é elevado o número de participantes nas atividades de pesca esportiva urbana. No Brasil, muitas cidades oferecem acesso conveniente aos locais de pesca, principalmente no litoral, onde os pescadores de todas as idades e níveis de habilidade podem participar de atividades de pesca esportiva, proporcionando importantes benefícios sociais e econômicos. A cidade de Santos é hoje, um dos principais pontos de pesca costeira urbana da região sudeste brasileira.

O presente trabalho teve como objetivo caracterizar a pesca esportiva praticada no "Deck do Pescador" de Santos, analisando o perfil socioeconômico dos pescadores esportivos, as técnicas e apetrechos utilizados, além das espécies mais procuradas e capturadas.

\section{MATERIAIS E MÉTODOS}

O local estudado, conhecido como "Deck do Pescador", está situado no município de Santos (Estado de São Paulo, Brasil). Trata-se de uma plataforma de pesca em forma de "T", localizada no Bairro 
Ponta da Praia, na entrada do canal do estuário, que avança $35 \mathrm{~m}$ sobre o mar, com $70 \mathrm{~m}$ de extensão, totalizando $630 \mathrm{~m}^{2}$ de área construída (Guia de Santos, 2012). Na entrada, há dois sanitários adaptados para deficientes físicos, uma loja de equipamentos de pesca e uma pequena lanchonete. A figura 1 mostra a localização do "deck" em Santos- SP.

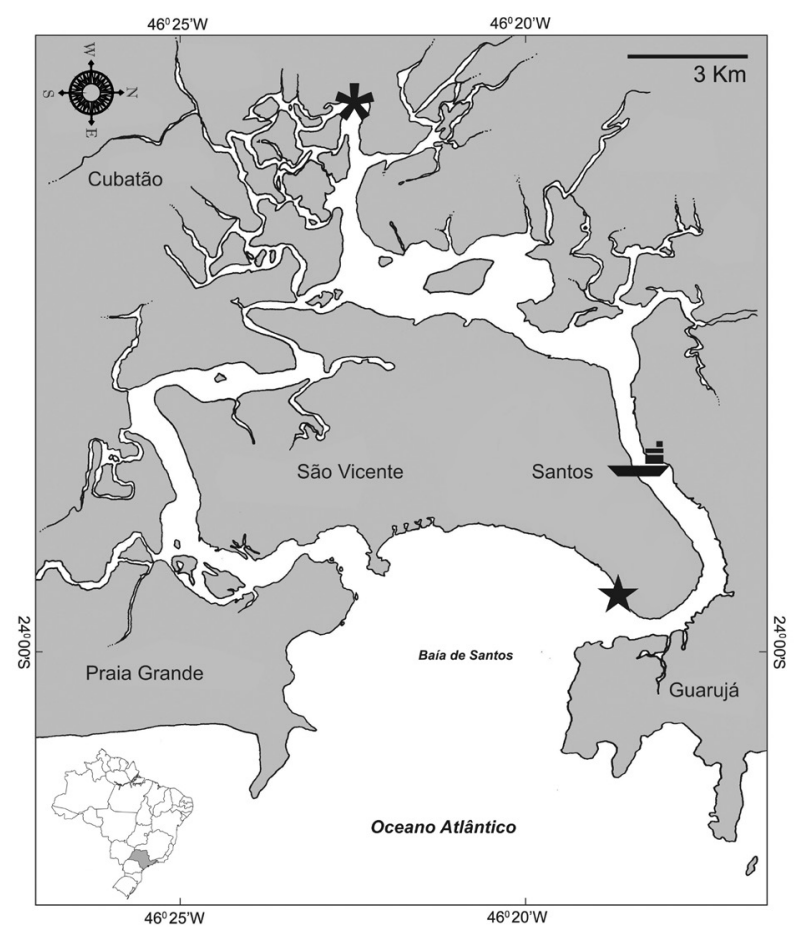

Figura 1 - Localização do "Deck do Pescador" de Santos (Estrela), do Porto (navio) e do complexo industrial de Cubatão (Asterisco).

O trabalho de campo foi realizado entre abril e setembro de 2012, em dias da semana (segunda a domingo) e períodos (manhã, tarde e noite) sorteados aleatoriamente para realização de entrevistas e contagem dos pescadores presentes. Em cada dia e período sorteado, procurou-se entrevistar todos os pescadores presentes no "Deck do Pescador". As entrevistas foram realizadas com auxílio de formulários semiestruturados onde, inicialmente eram obtidas informações sobre o perfil socioeconômico dos pescadores como idade, sexo, escolaridade, profissão, local de residência etc. $\mathrm{Na}$ segunda parte da entrevista eram verificadas as questões específicas da pesca, tais como documentos e licenças de pesca, frequência, duração e as espécies capturadas durante suas pescarias, as técnicas utilizadas e outros locais conhecidos de pesca. Quando os pescadores consentiam, os peixes eram contados, pesados e identificados no local, com a utilização do Guia de Peixes Estuarinos e Costeiros (Fischer et al., 2004). Todos os procedimentos foram realizados dentro dos preceitos éticos, sendo que o projeto foi aprovado pelo Comitê de Ética da Universidade Santa
Cecília (CAAE nº 07528712.8.0000.5513).

Com as informações qualitativas (sexo, escolaridade, etc.) foram calculadas as abundâncias relativas (em porcentagem), e com os dados quantitativos (idade, tempo de pescaria, etc.) foram calculadas as médias e desvios padrões dos dados quantitativos. Estes cálculos propiciaram uma melhor apresentação dos resultados, obtendo assim uma descrição mais clara das características dos pescadores e da pesca realizada nesse local.

\section{RESULTADOS}

Foram entrevistados 150 pescadores com idades que variaram entre 12 e 82 anos, média de 41 (d.p.=18) anos, sendo do sexo masculino $83 \%$ $(n=124)$ e do sexo feminino $17 \%(n=26)$. A maior parte dos pescadores $(50 \%)$ apresentou nível superior, seguidos pelos pescadores com o ensino médio (30\%), fundamental (16\%) e técnico (1\%), o restante (3\%) não informou sua escolaridade. Dentre os entrevistados, as atividades mais citadas foram os aposentados (14\%), estudantes (9\%), advogados (7\%), professores $(7 \%)$, motoboys $(6 \%)$, empresários $(4 \%)$, contadores $(3 \%)$, engenheiros (3\%) e taxistas (3\%). As rendas salariais foram em média de 5 (d.p.=4) salários mínimos, o que equivalia a $R \$ 3110,00$ (d.p. $=R \$ 2488,00$ ) visto que cujo valor do salário mínimo era de $\mathrm{R} \$ 622,00$. Isto equivalia a $\cup \$ 1532,02$ (d.p. $=\bigcup \$ 1225,62$ ), visto que a taxa de conversão era de $1 \cup \$=R \$ 2,03$.

Os pescadores entrevistados residiam em Santos (50\%), São Paulo (20\%), São Vicente (19\%), Praia Grande (3\%), Guarujá (2\%), São Bernardo do Campo (2\%), Araraquara (1\%), Campinas (1\%) e Jundiaí (1\%). Com relação aos $26 \%$ dos pescadores que residiam em outras cidades, se hospedaram na casa de amigos, familiares ou em hotéis. A distância percorrida pelos pescadores até o local da pesca variou de 500 metros até $350 \mathrm{~km}$, com uma média de 26 (d.p. $=50,4) \mathrm{km}$. O meio de transporte mais utilizado foi o automóvel (59\%), seguido pela bicicleta (19\%), ônibus $(12 \%)$ e motocicleta $(5 \%)$. Os outros pescadores $(5 \%)$ caminham até o ponto de pesca.

Alguns pescadores pescam no local há muitos anos. A média geral foi de 12,6 (d.p.=10,7) anos, o valor máximo de experiência na pesca esportiva foi de 50 anos e o mínimo com iniciantes que estavam pescando pela primeira vez. Foram registrados outros locais que os pescadores costumam frequentar tais como o "deck" de São Vicente (61\%), Guarujá (32\%), Bertioga (19\%), Perequê (17\%), Ilha as Palmas (17\%), Praia Grande (17\%), Mongaguá (13\%) e Mato Grosso (7\%).

Dentre os entrevistados, $64 \%$ não possuia a 
carteira de pesca esportiva e $36 \%$ dos pescadores disseram ter o registro de pescador amador, expedida pelo Ministério da Pesca e Aquicultura. Os pescadores esportivos pescavam geralmente acompanhados de amigos $(50 \%)$ ou familiares $(15 \%)$ e $35 \%$ deles costumavam pescar sozinhos. Os pescadores preferem pescar no "deck do pescador" pela boa estrutura, conforto e proximidade de suas casas. Muitos dos pescadores comentaram que o local é muito frequentado por pessoas conhecidas, tornando-se assim um local de convívio social, de fácil acesso, seguro e tranquilo para a pesca.

Durante o período de entrevistas, os pescadores foram contados, em dias semanais sorteados ao acaso. A Tabela 1 mostra a média de pescadores por dia da semana na localidade estudada. Os finais de semana apresentaram as maiores médias de pescadores, com 18,3 (d.p. =2,5) pescadores aos domingos e 17,3 (d.p. $=2,5$ ) pescadores aos sábados. Em todos os dias foram observados pescadores, sendo que a média geral foi de 10 (d.p. $=5,5$ ) pescadores por dia semanal.

Tabela 1 - Número médio de pescadores por dia da semana no "Deck do Pescador" em Santos (SP).

\begin{tabular}{ccc}
\hline \hline Dia & Pescadores/dia & Desvio padrão \\
\hline Segunda & 8,7 & 2,3 \\
Terça & 7,3 & 4,5 \\
Quarta & 4,6 & 1,8 \\
Quinta & 8,5 & 3,1 \\
Sexta & 5,5 & 2,2 \\
Sábado & 17,3 & 2,5 \\
Domingo & 18,3 & 2,5 \\
Geral & 10,0 & 5,5 \\
\hline \hline
\end{tabular}

Sobre a frequência de pesca, $47 \%$ dos pescadores entrevistados utilizam esse "deck" de 2 a 4 vezes por semana, $20 \%$ deles pescam todos os dias, outros $20 \%$ pescam 1 ou 2 vezes por mês e os $13 \%$ restantes pescam apenas duas a três vezes ao ano. O período da manhã foi menos citado, pois apenas $12(8 \%)$ pescadores preferiam pescar apenas pela manhã. $A$ preferência por tardes e noites foi muito maior, com $31 \%$ (46) e $30 \%$ (45) das citações respectivamente. Ainda uma boa parte dos entrevistados (32\%) pesca durante o dia inteiro. O tempo mínimo de cada pescaria foi de duas horas e o máximo de dez horas, a média foi de 5,0 (d.p.=2,1) horas. A quantidade de peixes capturados por dia de pesca variou entre os pescadores. Em média os pescadores capturaram 3 (d.p. $=1,4$ ) peixes por pescaria. Mais de $70 \%$ dos pescadores entrevistados pescam para seu consumo próprio, e $30 \%$ disseram que doam os peixes para amigos e familiares. Dentre os pescadores entrevistados $85 \%$ afirmaram que devolvem o peixe ao mar quando seu tamanho é muito pequeno, porém poucos conheciam os tamanhos mínimos de captura para suas espécies-alvo. Para $60 \%$ dos entrevistados, o resultado final por pescaria foi de 2 a $3 \mathrm{~kg}$ de peixes, outros $30 \%$ dos pescadores disseram que já pegaram mais de $7 \mathrm{~kg}$ de peixe em um dia e $10 \%$ dos pescadores disserem que nunca pegam peixe algum. O peso médio dos peixes capturados durante as entrevistas foi de 850,8 (d.p. $=962,5$ )g. As melhores épocas declaradas para a pesca foram durante os meses de abril a junho, onde foram capturados robalos (Centropomus spp.) de até $5,5 \mathrm{~kg}$.

A tabela 2 apresenta as espécies de peixes citadas como as mais capturadas pelos pescadores do "deck" de Santos. O peixe-espada foi mais capturado com apetrechos de pesca de superfície, sendo o peixe mais citado com um total de $30 \%$ dos entrevistados, seguido pelo robalo, pescada-branca, betara (ou perna-de-moça), pescada-amarela, corvina, parati, pampo, bagre, siri e peixe-sapo conforme dispostas na tabela 2.

Tabela 2 - Lista de espécies de peixes citadas como mais capturadas pelos pescadores do "deck" de Santos, organizada em ordem decrescente em relação ao número de citações.

\begin{tabular}{cccc}
\hline Nome Popular & $\begin{array}{c}\mathbf{N}^{\mathbf{d}} \text { de } \\
\text { citaçöes }\end{array}$ & $\%$ & Nomes cientificos das espécies identificadas \\
\hline Peixe-espada & 45 & 30 & Trichiurus lepturus \\
Robalo & 21 & 14 & Centropomus parallelus, C. undecimalis \\
Pescada-branca & 14 & 9,33 & Cynoscion spp. \\
Betara & 12 & 8 & Menticirrhus americanus \\
Pescada-amarela & 10 & 6,67 & Macrodon atricauda, \\
Corvina & 10 & 6,67 & Micropogonias furnieri \\
Parati & 10 & 6,67 & Mugil curema \\
Pampo & 9 & 6 & Trachinotus spp. \\
Bagre & 8 & 5,33 & Genidens genidens, G. barbus, Aspistor luniscutis, \\
& & & Cathorops spixii, \\
Siri-azul & 6 & 4 & Callinectes spp. \\
Peixe-sapo & 5 & 3,33 & Opsanus beta \\
\hline
\end{tabular}

As principais técnicas de pescaria foram a pesca de fundo (peixes que vivem mais próximos ao substrato), de superfície (peixes pelágicos) e pesca de siri. Na pesca de fundo ou lançamento de arrebentação são utilizados os seguintes materiais: vara, molinete (ou carretilha), anzol, linha e chumbada. A vara de pesca tem de 4 a $6 \mathrm{~m}$ de comprimento, com um molinete grande e de capacidade no mínimo de 250 metros com fio 0,40 milímetro ( $\mathrm{mm}$ ). No inverno utiliza-se fio $0,50 \mathrm{~mm}$ já que normalmente as águas são mais agitadas e turvas, já no verão, as águas mais claras e mar calmo permitem utilizar linhas mais finas até fio $0,30 \mathrm{~mm}$ e de boa qualidade. Ainda segundo os pescadores, as chumbadas utilizadas podem variar de $100 \mathrm{~g}$ a $300 \mathrm{~g}$ em função do estado do mar. Pode utilizar esse método em qualquer estado da maré. Na pesca de superfície, para captura do peixe-espada principalmente, além dos materiais mencionados acima, são também utilizadas boias, rolhas de cortiça e luminárias, pois essa pesca é praticada geralmente à noite. Neste 
tipo de pesca, os pescadores recomendaram utilizar equipamento de ação média pesada, composto de vara, carretilha ou molinete com capacidade para $100 \mathrm{~m}$ de linha com $0,40 \mathrm{~mm}$ de diâmetro e anzóis tipo maruseigo de tamanho $4 / 0$ a 6/0. Existem várias formas de se pescar o peixe espada já que ele vive tanto em locais fundos como rasos. Os pescadores recomendaram a utilização de uma boia, de preferência luminosa, pois eles costumam pescar à noite. Para pescar espadas com iscas naturais, a mais utilizada foi a sardinha. As iscas artificiais de meia água também foram eficientes para captura de espada, tanto na modalidade de corrico como na de arremesso.

De forma geral, as iscas naturais mais utilizadas para a pesca esportiva de Santos foram sardinha, manjuba, camarão morto, camarão vivo, alguns pescadores ainda citaram o corrupto (crustáceo) e a minhoca (tabela 3).

Tabela 3 - Iscas naturais mais utilizadas pelos pescadores esportivos de Santos.

\begin{tabular}{ccc}
\hline Nome popular & $\begin{array}{c}\text { Porcentagem } \\
\text { das citaçōes } \\
(\%)\end{array}$ & Nome científico \\
\hline Sardinha e manjuba & 40 & Sardinella brasiliensis e Anchoviella lepidentostole \\
Camarão morto & 25 & Farfantepenaeus brasiliensis e Farfantepenaeus paulensis \\
Camarão vivo & 20 & Litopenaeus schmitti \\
Corrupto & 10 & Callichirus spp. \\
Minhoca & 5 & Pherentina hawaiana \\
\hline \hline
\end{tabular}

Finalmente, para a pesca do siri utiliza-se um puçá, isca e um saco (para guardar os siris capturados). O puçá consiste em aro de metal fechado com um pedaço de rede. A isca deve ser amarrada na rede que cobre o puçá, e pode ser um peixe ou um pedaço qualquer de carne tal como pescoço de frango. Mergulha-se o puçá na água, e de tempos em tempos retira-se, para ver se algum siri foi pego. Caso venha o siri, o mesmo deve ser retirado do puçá e colocado em um saco. Os pescadores ainda lembraram que os siris filhotes devem ser devolvidos ao mar, para que garanta sempre a procriação deles.

Durante os meses de julho e agosto foi observado um aumento expressivo no número de pescadores do "deck". Tal diferença é decorrente de temporada das férias e do clima favorável, sem a ocorrência de períodos chuvosos, típicos dessa época do ano. Isto pode ser observado na figura 2 que mostra a porporção de citações dos meses adequados para a pesca declarados pelos pescadores entrevistados. Segundo eles, os meses de verão (janeiro a março) a água está quente e desagradável para os peixes, que preferem permanecer em regiões mais distantes da costa. A partir do mês de abril as condições da água começam a ficar mais favoráveis e várias espécies "encostam" nas áreas estuarinas. Ainda segundo os pescadores, essas condições favoráveis permanecem até os meses de novembro e dezembro, quando a água esquenta e "espanta" os peixes.

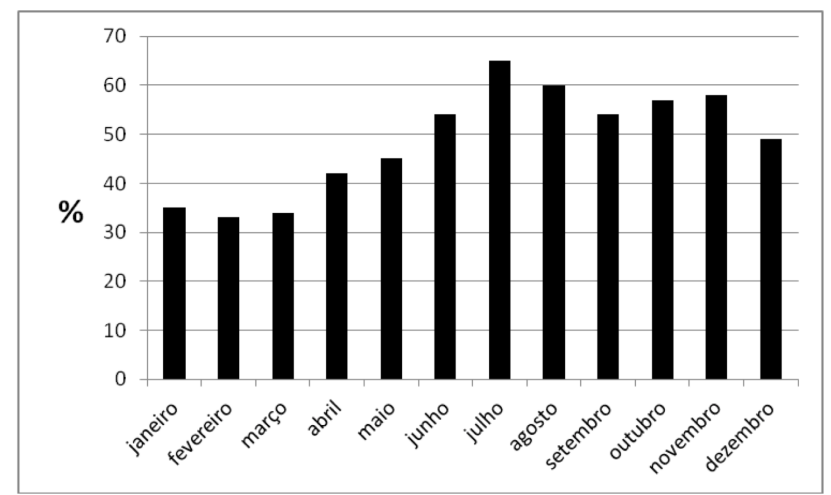

Figura 2 - Porcentagem de citações dos meses adequados para a prática da pesca esportiva no "Deck do Pescador" em Santos $(n=150)$.

A qualidade do pesqueiro foi classificada como bom para $61 \%$ dos entrevistados, regular para $26 \%$ e ruim para $13 \%$. Ainda segundo os entrevistados, a qualidade do pesqueiro vem piorando. A pesca do camarão, utilizando redes de arrasto com malhas finas, realizada muito próxima da costa, capturam muitos peixes pequenos, que são descartados e levados às praias pela maré. Este foi o principal problema para $72 \%$ dos entrevistados. Outra parte dos pescadores entrevistados (16\%) citou também a perda da qualidade da água, relacionada com os problemas ambientais provocados no Porto, como motivo da piora da qualidade do pesqueiro, com a diminuição do número e tipos de peixes, quando comparados aos anos anteriores. Outro conflito foi observado com os turistas transeuntes, que invadem a plataforma de pesca para observar e fotografar os grandes navios que passam no canal em frente, rumo ao Porto de Santos. O excesso de pessoas na plataforma tem causado pequenos acidentes e danos aos equipamentos de pesca.

\section{DISCUSSÃO}

O perfil do pescador de Santos é muito semeIhante ao apresentado por Barcellini et al. (2013) para o pescador do Complexo Estuarino-Lagunar de Iguape-Cananéia localizado $200 \mathrm{~km}$ ao sul, ainda no estado de São Paulo. Por outro lado, uma pesquisa feita no Nordeste do Brasil por Freire (2005) mostrou que a variação de idade foi bem diferente desta pesquisa, sendo que no Nordeste os pescadores tinham de 30 a 49 anos, uma notável diferença, pois, em Santos foram registrados idades entre 12 e 82 anos. A predominância de homens foi a maior semelhança entre alguns trabalhos realizados. Freire (2005) tam- 
bém verificou que $95 \%$ dos pescadores nordestinos são homens, e na Praia do Cassino (RS), Basaglia \& Vieira (2005) encontraram $94 \%$ dos pescadores do sexo masculino.

Em Santos, mais de $50 \%$ dos pescadores entrevistados são pessoas instruídas (nível superior), com uma renda salarial mais alta daquela encontrada na Praia do Cassino (Basaglia \& Vieira, 2005). Ainda sobre o grau de escolaridade, nota-se uma diferença considerável em relação ao trabalho de

Carrião et al. (2012) no porto de Peruíbe (SP) onde apenas $11 \%$ dos entrevistados possuíam ensino superior completo. No Rio Sorocaba, Tarciani \& Barrella (2009) verificaram que nenhum pescador possuía ensino superior completo e também não tinham o registro de pescador amador. Na Ponte dos Franceses no Rio Grande (RS), mais de $50 \%$ dos pescadores apresentaram baixo nível de instrução e renda salarial baixa (Harayashiki et al., 2008).

O elevado número de pessoas aposentadas e estudantes, associados às altas frequências diárias e semanais indicam também que os pescadores, além de possuírem tempo disponível, residem próximo aos pesqueiros e se deslocam menos de $50 \mathrm{~km}$ para realizar suas pescarias. Tal situação é muito similar aos pescadores de outras partes do mundo, tais como em Portugal (Veiga et al., 2010) e na Noruega (Mokness et al., 2011).

Apesar da larga experiência que o pescador do "Deck" de Santos possui, a pesca pode ser considerada como uma atividade de lazer, sendo realizada em grupos de parentes e amigos pela maior parte dos entrevistados, que em muitos casos (cerca de 90\%) não se importam em nada capturar. O contato com a natureza, o convivio agradável com pessoas (parentes e amigos) foram os principais motivos para classificar os locais de pesca como de boa qualidade, apesar da piora comparada com anos anteriores. Isto também ocorreu com os pescadores da Barra do Una, na Estação Ecológica Juréia-Itatins (Ramires \& Barrella, 2001), na Cachoeira de Emas, no rio Mogi-Guaçu (Peixer \& Petrere Jr., 2009), na Praia do Cassino (Basaglia \& Vieira, 2005).

A elevada proporção de pescadores sem a licença de pesca (64\% dos entrevistados) está relacionada com a baixa frequência de agentes de fiscalização, como também mencionado por Tarcitani \& Barrella (2009), situação semelhante a que ocorre em outras partes do Estado de São Paulo (Souza \& Molina, 2004; Carrião et al., 2012) e do Brasil (Chiappani, 2006).

Apesar da larga experiência do pescador que frequenta o "Deck" de Santos, a pesca pode ser considerada como atividade de lazer, sendo realizada na companhia de parentes e amigos pela maior parte dos entrevistados (65\%), que em muitos casos não se importam em nada capturar. O contato com a natureza, a infraestrutura do local e o convívio agradável com pessoas foram os principais motivos para classificar os locais de pesca como de boa qualidade, apesar da piora comparada com anos anteriores. Isto também ocorreu com os pescadores da Barra do Una, na Estação Ecológica Juréia-Itatins (Ramires \& Barrella, 2001), na Cachoeira de Emas, no rio Mogi-Guaçu (Peixer \& Petrere Jr., 2009), na Praia do Cassino (Basaglia \& Vieira, 2005) e em eventos de pesca na região do Parque Nacional de llha Grande (Zacarkim et al., 2005). Por outro lado, a captura de peixes (quantidade e variedade) é o principal fator para que uma pescaria seja realmente satisfatória para os pescadores que vão ao Pantanal (Moraes \& Seidl, 2000), ao rio Araguaia (Carvalho \& Medeiros, 2005) e para a mesma a Praia do Cassino (Basaglia \& Vieira, 2005). Na costa de Portugal, Veiga et al. (2010) verificaram que $73 \%$ dos pescadores pescam sozinhos com objetivo de captura de peixes, da mesma forma que os pescadores do Guarujá. Arlinghaus \& Mehner (2004) verificaram que os pescadores urbanos de Berlim (Alemanha), eram mais orientados à captura de peixes para ganhar alguma competição do que aqueles de origem rural.

Através das contagens realizadas, foi possível verificar que a quantidade média de pescadores foi de 10,0 (d.p. $=5,5$ ) pescadores/dia, sendo que os finais de semana (sábados e domingos) os dias de maior frequência. Na Ponta das Galhetas (Guarujá, SP), Tsuruda et al. (2013) verificaram que os domingos com 18 (d.p. $=7,9$ ) pescadores e as noites das quartas-feiras com 12 (d.p. $=9,2$ ) pescadores foram os dias com maior frequência, com uma média geral de 7,7 (d.p.=5,8) pescadores dia.

A quantidade de pescado capturado no período do trabalho foi menor do que a dos anos anteriores (2010 e 2011), que segundo os pescadores, havia maior riqueza de espécies e maior abundância de indivíduos. Ainda comentaram que atualmente, passam muito tempo pescando, e mesmo assim, muitas vezes não conseguem capturar nenhum peixe. Utilizando o número de pescadores, o tempo médio de cada pescaria foi de 5,0 (d.p. $=2,1$ ) horas e o peso médio de pescado capturado por dia $(850,8 \mathrm{~g}$ d.p. $=962,5) \mathrm{g}$, foi possível obter uma estimativa de captura de 1314,8 (d.p. $=1919,1) \mathrm{kg}$ de peixes no período estudado (entre abril e setembro de 2012), representando $2,94 \%$ dos $44650 \mathrm{~kg}$ de pescado desembarcado (peixes capturados durante os arrastos de camarão) no mesmo período, no terminal de Santos pelos pescadores de camarão que atuam na região (fonte: Instituto de Pesca www.pesca.sp.gov.br). Porém, tal relação entre a pesca esportiva e a comercial pode estar 
subestimada visto que a frota de barcos que pescam com redes de arrasto atuam numa área maior, abrangendo também o trecho que vai da llha da Moela até a Praia da Enseada, em Bertioga (dos Santos, 2008). Matsuishi et al. (2002), relataram que pescadores amadores capturaram 3 vezes mais que os pescadores profissionais devido às regras de gestão pesqueira impostas no Lago Toya (Japão). Ainda é importante ressaltar que estimativa do peso capturado pela pesca esportiva está subdimensionado devido à falta de informações sobre as capturas do período mais quente do ano (outubro a março) nessa localidade (Paiva Filho \& Toscana, 1987; FAO, 2002a e b; Barreiros et al., 2004; Godefroid et al., 2004; Peixer \& Petrere Jr, 2009; Freire, 2005 e 2010; Llompart et al., 2012 e 2013). Font \& Lloret (2011) verificaram situações semelhantes na pesca realizada ao longo da costa da reserva marinha de Crap de Creus (NW Mediterrâneo), com uma captura anual de três toneladas, muito abaixo das capturas das pescarias comerciais realizadas na área.

As iscas utilizadas pelos pescadores esportivos de Santos são obtidas no do estuário. O camarãobranco (Litopenaeus schmitti) possui uma fase do seu ciclo de vida que possibilita sua capturada por tarrafa (Santos et al., 1988) e mais comumente por gerivá. A pesca de gerivá tem sido muito observada no estuário de Santos, sendo praticada por pescadores artesanais para a venda de camarão vivo (Chaves \& Robert, 2003). O corrupto é capturado com uma bomba de sucção, em São Vicente devido à uma lei municipal (Lei Municipal $n^{\circ} 850$, de 1992), que proíbe a captura desse crustáceo nas praias santistas. Já na pesca com minhocas, os pescadores que mencionaram essa isca, as traziam de suas cidades de origem, no interior de São Paulo, porém sem muito sucesso na captura de peixes.

Ainda cabe ressaltar que durante a realização desse trabalho, não foi observada fiscalização por parte dos órgãos competentes, no que diz respeito ao documento obrigatório de pesca e quanto ao tamanho e quantidade de peixes capturados. O que indica a necessidade de a implantação ou o aprimoramento de um programa de controle da pesca esportiva na região de Santos. Isto corrobora com a afirmação de Diegues (2001) que afirma existir graves problemas que impedem a implantação de uma gestão integrada da zona costeira brasileira.

A maior parte dos pescadores entrevistados (cerca de $80 \%$ ) afirma que a pesca comercial está prejudicando a pesca esportiva, pois os barcos arrastam suas redes na entrada da baia de Santos, provocando uma drástica redução na quantidade de peixes no estuário. Tal afirmação é baseada no fato que muitos peixes rejeitados pelos barcos de pesca de camarão que atuam na Baia de Santos, chegam mortos às praias de Santos, provocando a indignação dos pescadores. Apesar de se considerarem "defensores da natureza", os pescadores desportivos aqui analisados, não conhecem os tamanhos permitidos para a pesca das espécies que capturam. Muitos deles também não possuem a licença de pesca o que dificulta organização de estatísticas para o gerenciamento da pesca. A fiscalização da pesca recreacional é praticamente inexistente e muitos pescadores resistem a qualquer tipo monitoramento. Devido a estes fatos, não é possível obter bons resultados de campanhas educativas, para promover um comportamento humano em consonância com o uso sustentável dos ecossistemas aquáticos como comentam Lewin et al. (2006).

\section{REFERÊNCIAS BIBLIOGRÁFICAS}

Arlinghaus, R. \& Mehner, T. 2004. A ManagementOrientated Comparative Analysis of Urban and Rural Anglers Living in a Metropolis (Berlin, Germany) Environmental Management 33 (3) : 331-344. doi: 10.1007/s00267-004-0025-x

Basaglia, T.P. \& Vieira, J.P. 2005. A pesca amadora recreativa de caniço na praia do Cassino, RS: Necessidade de informações ecológicas aliada à espécie alvo. Braz. J. Aquat. Sci. Technol. $9(1): 25-29$.

Barcellini, V.C.; Motta, F.S.; Martins, A.M. \& Moro, P.S. 2013. Recreational anglers and fishing guides from an estuarine protected area in southeastern Brazil: Socioeconomic characteristics and views on fisheries management. Ocean \& Coastal Management 76: 23-29.

Barreiros, J.P.; Figna, V.; Hostim-Silva, M. \& Santos, R.S. 2004. Seasonal Changes in a Sandy Beach Fish Assemblage at Canto Grande, Santa Catarina, South Brazil. Journal of Coastal Research 20(3): 862-870.

Carrião, S.M.; Salmon, T.; Cunningham, P.T.M.; Suhogusoff, V.G. 2012, Caracterização da pesca e do pescador desportivo de arremesso do Porto de Peruibe - Litoral Sul de São Paulo. XV Simpósio de Biologia Marinha, UNISANTA. Santos. Disponível em: http://sites.unisanta.br/simposiobiomar/2012/ trabalhos2012/206.pdf. Acesso em: 13, dez. 2012.

Carvalho, A.R. \& Medeiros, E.R. 2005. Levantamento socioeconômico e da composição de espécies entre os turistas que praticam a pesca recreativa no Rio Araguaia, região de Aruanã (GO). Revista Saúde e Ambiente / Health and Environment Journal, 6 (2): 23-31.

Chaves, P.T.C. \& Robert, M.C. 2003, Embarcações, artes e procedimentos da pesca artesanal no 
litoral sul do Estado do Paraná, Brasil. Atlântica, Rio Grande, 25(1): 53-59.

Chiappani, L.H.B. 2006. Caracterização e avaliação da atividade de pesca amadora na praia de Camburi, Vitória-ES. Monografia (Bacharel em Oceanografia) - Universidade Federal do Espírito Santo, Espírito Santo. 50pp.

Cooke, S.J. \& Cowx I.G. 2004. The role of recreational fishing in global fish crises. BioScience 54(9): 857-859.

Cooke, S.J. \& Cowx, I.G. 2006. Contrasting recreational and commercial fishing: Searching for common issues to promote unified conservation of fisheries resources and aquatic environments. Biological Conservation 128: 93-108.

Dieges, A.C. 2001. Regional and domestic mass tourism in Brazil: an overview. In Ghimire K (ed) The native tourist: mass tourism within developing countries, 55-85.

dos SANTOS, J.L.; SEVERINO-RODRIGUES, E. \& André, M. 2008. Estrutura populacional do camarão-branco Litopenaeus schmitti nas regiões estuarina e marinha da Baixada Santista, São Paulo, Brasil. Boletim do Instituto de Pesca , 34(3): $375-389$.

FAO. 1997. Inland fisheries. FAO Fisheries Department Technical Guidelines for Responsible Fisheries No 6 (Technical guidelines for the sustainable management of inland fisheries). FAO, Rome.

FAO. 2002a.FAO yearbook. Fishery statistics. Catches and landings. 2000. Food and Agriculture Organization of the United Nations, Rome.

FAO. 2002b. Fishery country profile. The Federative Republic of Brazil. www.fao.org/fi/fcp/fcp.asp, Accessed 10 March 2002.

FAO .2012. Recreational Fisheries. FAO Technical Guidelines for Responsible Fisheries 13. http:// www.fao.org/docrep/016/i2708e/i2708e00.htm. Accessed 14 March 2014.

Fischer, L.R.; Pereira, L.E. \& Vieira, J.P. 2004 Peixes Estuarinos e Costeiros. $1^{\text {a }}$ ed. Rio Grande: Ecoscientia. $125 \mathrm{p}$.

Freire, K.M.F. 2005. Recreational fisheries of northeastern Brazil: inferences from data provided by anglers. In: Kruse, G.H.; Gallucci, V.F.; Hay,D.E.; Perry, R.I.; Peterman, R.M.; Shirley, T.C.; Spencer, P.D.; Wilson, B.; Woodby, D. Fisheries assessment and management in data-limitedsituations. Anchorage: Alaska Sea Grant College Program, University of Alaska Fairbanks.p.377-394.

Freire, K.M.F. 2010. Unregulated Catches From Recreational Fisheries Off Northeastern Brazil. Atlântica, 32(1): 87-93.

Font, T. \& Lloret, J. 2011. Biological implications of recreational shore angling and harvest in a marine reserve: the case of Cape Creus. Aquatic Conservation: Marine and Freshwater Ecosystems 21(2), 210-217.

Godefroid, R.S.; Spach, H.L.; Santos, C.; MacLaren, G. \& Schwarz Jr., R. 2004. Mudanças temporais na abundância e diversidade da fauna de peixes do infralitoral raso de uma praia, sul do Brasil. Iheringia, Sér. Zool., 94(1):95-104.

Guia de Santos. Disponível em: http://www. turismosantos.com.br/guia-de-santos/locais/ir/ atracoes-em-santos/deck-do-pescador, Acessado em 14 de agosto de 2012.

Harayashiki, C.A.Y.; Furlan, F.M. \& Vieira, J.P.2008 Perfil sócio econômico dos pescadores da Ponte dos Franceses, Rio Grande, RS, Brasil. Bol. Inst. Pesca, 37(1): 93 - 101, 2011

Lewin, W.C.; Arlinghaus, R. \& Mehner, T. 2006. Documented and potential biological impacts of recreational fishing: insights for management and conservation. Reviews in Fisheries Science 14(4): 305-367.

Llompart, F.M.; Colautti, D.C. \& Baigún, C.R.M. 2012. Assessment of a major shorebased marine recreational fishery in the southwest Atlantic, Argentina, New Zealand Journal of Marine and Freshwater Research, 46(1): 57-70. doi: 10.1080/00288330.2011.595420

Llompart, F.M.; Calautti, D.C.; Cruz-Jiménez, A.M. \& Baigún, C.R.M. 2013. Seasonal pattern of the coastal fish assemblage in Anegada Bay, Argentina. Journal of the Marine Biological Association of the United Kingdom 93(08): 2273-2285. doi: 10.1017/ S0025315413001045

Matsuishi, T.; Narita, A. \& Ueda, H. 2002 Population assessment of sockeye salmon Oncorhynchus nerka caught by recreacional angling and commercial fishery in Lake Toya, Japan. Fisheries Science, 68: 1205-1211.

Moksness, E.; Gjøsæter, J.; Lagaillarde, G.; Mikkelsen, E.; Moland Olsen, E.; Sandersen, H.T. \& Helge Vølstad, J. 2011. Effects of fishing tourism in a coastal municipality: a case study from Risør, Norway. Ecology and Society 16(3): 11. DOI:10.5751/ES-04290-160311

Moraes, A.S. \& Seidl, A.F. 2000. Perfil dos pescadores esportivos do sul do Pantanal. Corumbá: Embrapa Pantanal, 2000. 45 p. (Embrapa Pantanal. Circular Técnica, 24).

O'Toole, A.C.; Hanson, K.C. \& Cooke, S.J. 2009. The effect of shoreline recreational angling activities on aquatic and riparian habitat within an urban environment: implications for conservation and management. Environmental management, 44(2): 324-334.

Paiva Filho, A.M. \& Toscano, A.P. 1987. Estudo 
Barrella, W., et al. (2016). Pesca esportiva no deck do pescador de Santos - SP.

Comparativo E Variação Sazonal da Ictiofauna Na Zona Entremarés do Mar Casado-Guarujá e Mar Pequeno-São Vicente,SP. Boletim Instituto Oceanográfico USP 35(2): 153-165.

Peixer, J. \& Petrere Júnior, M. 2009. Socio-economic characteristics of the Cachoeira de Emas smallscale fishery in Mogi-Guaçu River, State of São Paulo, Brazil. Brazilian Journal of Biology, 69(4): 1047-1058.

Pitcher, T.J. 1999. Fishing for Fun, Food and Profit. In Pitcher,T.J. (Ed.) Evaluating the benefits of recreational fishing. Fisheries Centre Research Reports 7 (2).

Prado, R.A. 1999. Pesca Esportiva. Fishing news.6 (67)::8.

Ramires, M. \& Barrella, W. 2001. A pesca esportiva como alternativa econômica em uma população caiçara da Estação Ecológica Juréia-Itatins. PUCSP Ciências Biologicas e Ambientais 3(1): 39-51

Santos, R.A.; Sckendorff, R.W.V.E \& Amaral, M.L.F.M. 1988, Espécies mais comercializadas na região Sudeste do Brasil e respectivas artes e embarcações utilizadas nas capturas. Boletim Técnico Instituto de Pesca, 6: 1-31.

Soares, D. 2001. Pesca amadora. Ed. Nobel, São Paulo, SP, $86 \mathrm{p}$.

Souza, M.R. \& Molina, S.M.G. 2004. Influências da pesca esportiva no modo de vida dos pescadores caiçaras do Vale do Ribeira (SP). In: $7^{\circ}$ Encontro Latino Americano de Iniciação Científica e $4^{\circ}$ Encontro Americano de Pós-Graduação Universidade do Vale do Paraíba, São José dos Campos, p.1197-1200.
Tarciani, F.C. \& Barrella, W. 2009. Conhecimento Etnoictiológico dos Pescadores Desportivos do Trecho Superior da Bacia do Rio Sorocaba, Revista Eletrônica de Biologia, 2 (2): 1-28.

Tsuruda J.M.; do Nascimento, R.B.; Barrella, W.; Ramires, M. \& Rotundo, M.M. 2013. Fishing and socio-economic profile of sportive anglers of Galhetas Tip, Asturias Beach-Guarujá (SP). Unisanta BioScience, 2(1), 22-34.

Veiga, P.; Ribeiro, J.; Gonçalves, J.M.S. \& Erzini, K. 2010. Quantifying recreational shore angling catch and harvest in southern Portugal (north-east Atlantic Ocean): implications for conservation and integrated fisheries management. Journal of Fish Biology, 76(9): 2216-2237

Zacarkim, C.E.; Ferrari, E. \& Freitag, M. 2005. Perfil Do Pescador Amador Participante De Eventos De Pesca Na Região Do Parque Nacional De Ilha Grande.http://www.ibama.gov.br/pesca-amadora/ wp-content/files/id29_perfi_pescador.pdf. Acessed 12 July 2013

Submetido: Março/2014

Revisado: Agosto/2014

Aceito: Agosto/2014 